\title{
ROBUST MICRODEVICE MANUFACTURING BY DIRECT LITHOGRAPHY AND ADHESIVE-FREE BONDING OF OFF-STOICHIOMETRY THIOL-ENE-EPOXY (OSTE+) POLYMER
}

\author{
A. Vastesson ${ }^{1}$, X. Zhou ${ }^{1}$, N. Sandström ${ }^{1}$, F. Saharil ${ }^{1}$, O. Supekar ${ }^{2}$, G. Stemme ${ }^{1}$, \\ $W$. van der Wijngaart ${ }^{1}$ and T. Haraldsson ${ }^{1}$ \\ ${ }^{1}$ KTH Royal Institute of Technology, Stockholm, SWEDEN \\ ${ }^{2}$ India Institute of Technology (IIT), Bombay, INDIA
}

\begin{abstract}
We here demonstrate, for the first time, the use of direct lithography in off-stoichiometry thiol-ene-epoxy (OSTE +$)$ to fabricate a microdevice. First, the photolithographic property of OSTE+ is shown by using a photomask to create micropillars with an aspect-ratio of $1: 10$ in a $2 \mathrm{~mm}$ thick layer. Secondly, a three-layer OSTE + microdevice containing in-/outlet holes, channels, and pillars is fabricated by using a combination of direct lithography and adhesive-free dry bonding. The resulting microdevice shows desirable properties, such as leak-free filling and hydrophilic surfaces. This fabrication method enhances the microstructurability of OSTE+ beyond that of conventional soft lithography replica molding of other polymers, such as PDMS.
\end{abstract}

\section{KEYWORDS}

Microfluidics, soft lithography, photolithography, bonding, microdevice fabrication, thiol-ene, thiol, epoxy, OSTE+

\section{INTRODUCTION}

Microfluidic devices require controlled surface properties and well-defined structures such as pillars, channels, and access ports. To also enable low-cost manufacturing and rapid prototyping, the use of polymeric materials for fabricating microfluidic devices has gained a great interest $[1,2]$. In academia, two commonly used polymer materials for microfluidic device fabrication are PDMS and SU8. However, the use of these two materials has several limitations, where PDMS is limited by the poor mechanical stability, leaching of material components, invariable surface chemistry, and the risk of destroying small structures (such as micropillars) during demolding. SU8 allows high aspectratio photolithography, but is limited due to unreactive surface chemistry in the native material and requires solvent evaporation (soft baking), which limits the film thickness due to cracking of the material when layers exceed a few hundred microns.

To find more suitable materials for microfluidic device fabrication, some researchers have investigated the use of thiol-ene polymers; that allows direct lithography for facile fabrication of microstructures [3], enables surface modification of microfluidic devices [4], and allows fabrication and bonding of microfluidic devices [5]. Carlborg et al. introduced off-stoichiometry thiol-ene (OSTE) polymers [6] for soft lithography fabrication of microfluidic devices. Furthermore, Karlsson et al. showed a novel photolithography mechanism in OSTE polymers [7], which enables fabrication of high-resolution microstructures. Whereas OSTE is superior to conventional thiol-ene polymers in terms of easy and robust surface modifications, there remain three main disadvantages of using OSTE polymers: 1) due to the specific surface chemistry of OSTE, two different types of OSTE polymers are required for good bonding; 2) for bonding OSTE to other materials than itself, surface modification is required; and 3) unreacted monomers have been observed to leach out of the polymer matrix [6].

To counter these problems, we recently introduced an extension to OSTE polymers called off-stoichiometry thiol-ene-epoxy (OSTE+) [8]. OSTE+ polymers are synthesized via a two-step combined photo- and anionic polymerization process. After the first polymerization step, OSTE+ has the ability to directly react with almost any dry surface. This is due to the presence of free unreacted thiol and epoxide groups at the surface of the OSTE+ polymer. Thus, there is no requirement for using adhesives or surface treatment during bonding. After the second polymerization step, OSTE+ shows minimal leakage of uncured monomers since the free thiols and epoxides have reacted in the fully cured polymer network.

To avoid soft lithography replica molding and to extend the utility of the recent advances using OSTE lithography, it is desirable to fabricate microdevices in OSTE+ by using direct lithography. In this work, the photolithographic properties of OSTE+ were investigated by using an ultraviolet light-source to create high aspectratio OSTE+ micropillars onto a silicon substrate. In addition, an OSTE+ microdevice was fabricated using a combination of direct lithography and adhesive-free bonding.

\section{FABRICATION}

For the fabrication of micropillars on a silicon substrate, OSTE+ pre-polymer was first prepared by mixing 1,3,5-Triallyl-1,3,5-triazine-2,4,6(1H,3H,5H)trione (TATATO, Mercene Labs, Sweden), pentaerythritol tetrakis(3-mercaptopropionate) (PETMP, Mercene Labs, Sweden), and D.E.N. 431 epoxy novolac resin (Dow Corning GmbH, Germany) in a functional group molar ratio of 1:1.2:0.2 (called OSTE+ 1:1.2:0.2). Into this mixture, $1 \mathrm{wt} \%$ photo-latent base (BASF $\mathrm{GmbH}$, Germany) and $0.5 \mathrm{wt} \%$ Lucirin TPO-L photoinitiator (BASF GmbH, Germany) were added. The silicon substrate was silanized to ensure instantaneous bonding of OSTE+. For this purpose, the silicon substrate was immersed into a mixture of $5 \mathrm{wt} \%$ Z-6030 Silane (Dow Corning Co., USA) in methanol for $10 \mathrm{~min}$ followed by 10 min drying at $110{ }^{\circ} \mathrm{C}$ in an oven. The OSTE+ 1:1.2:0.2 pre-polymer was poured onto a silicon substrate with a 
(1) UV-light exposure $\left(500 \mathrm{~s}, 12 \mathrm{~mW} / \mathrm{cm}^{2}\right)$

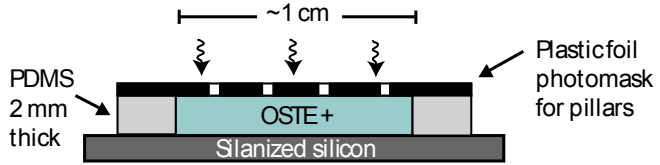

(2) Remove photomask and PDMSframe Develop OSTE + micropillars in acetone

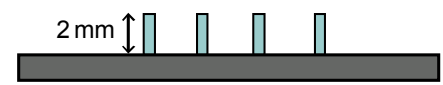

Figure 1: Process used for direct lithography of OSTE+ micropillars on silicon substrates

surrounding $2 \mathrm{~mm}$ thick PDMS spacer-frame. A plastic foil dark-field photomask, which had transparent circular areas of $200 \mu \mathrm{m}$ in diameter, was clamped to the PDMS frame thus defining the thickness of the layer of prepolymer OSTE+. Photopolymerization was performed using a collimated near-UV mask aligner (OAI, Milpitas, USA) to expose the OSTE+ 1:1.2:0.2 for $500 \mathrm{~s}$ at 12 $\mathrm{mW} / \mathrm{cm}^{2}$. After removing the plastic foil photomask the micropillars (Figure 1) were developed in acetone for 30 s.

The microfluidic device demonstrator was fabricated by preparing three layers of OSTE+, using a combination of molding and photolithography, followed by dry, adhesive-free bonding (Figure 2). The OSTE+ formulation used for the microdevice was different from that used for the micropillars, and had a functional group molar ratio of 1:1.4:0.4 for TATATO, PETMP, and D.E.N. 431 (called OSTE+ 1:1.4:0.4). This was to increase the concentration of functional groups present on the surface after the first polymerization step. $1 \mathrm{wt} \%$ photo-latent base and $0.5 \mathrm{wt} \%$ TPO-L were added to the OSTE+ $\quad 1: 1.4: 0.4$ formulation.

\section{A Bottom-layer}
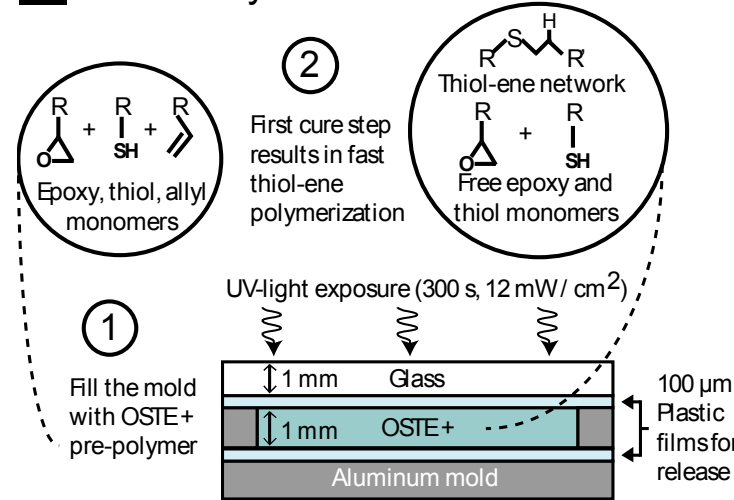

C Top-layer

(1)

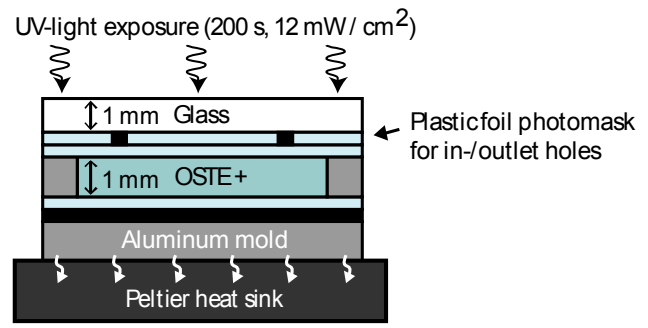

(2)

Remove the uncured OSTE + polymer in acetone

\section{B Middle-layer}

(1)

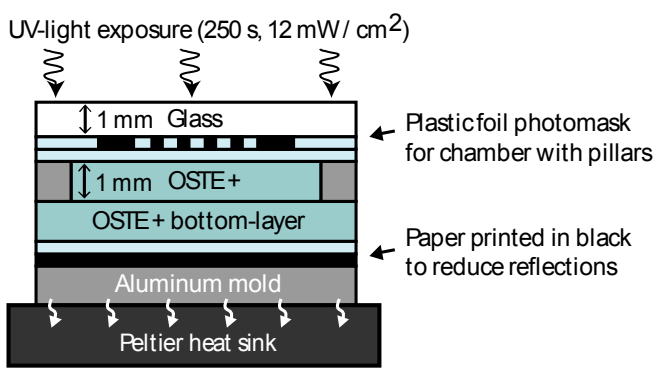

(2)

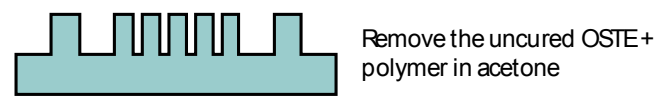

D Bonding of layers

(1) Align and clamp to middle-layer

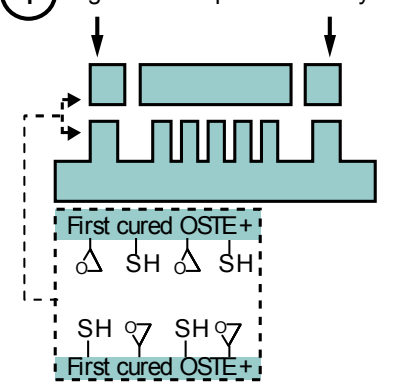

Complete microdevice!

(2) UV-light exposure $\left(500 \mathrm{~s}, 12 \mathrm{~mW} / \mathrm{cm}^{2}\right)$

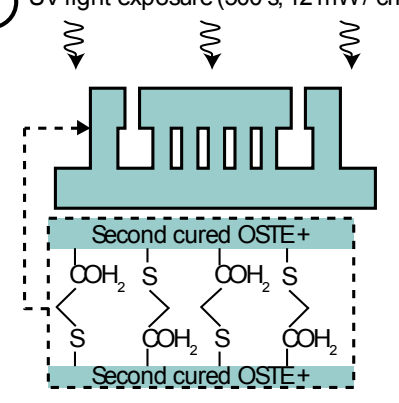

Second curing step results in a fully cured thiol-ene-epoxy network and the two OSTE + layers are bonded together

* Optional: thermally accelerated cure in oven $1 \mathrm{~h}$ at $75^{\circ} \mathrm{C}$

Figure 2: Process flow for fabrication of an OSTE+ microdevice. A)-C) Fabrication of three OSTE+ layers. D) Bonding of the layers. 
For the photolithography, plastic foil photomasks were used to define structures and in-/outlet holes. Each photomask was placed onto a $100 \mu \mathrm{m}$ thick release film that was in direct contact with the pre-polymer. To avoid leakage of pre-polymer, the different layers of the mold were pressed together using clamps. The microdevice was fabricated in four main steps (A-D). In step A (Figure $2 \mathrm{~A})$, the $1 \mathrm{~mm}$ thick OSTE+ bottom-layer was polymerized in an aluminum-mold by UV-light exposure for $300 \mathrm{~s}$ at $12 \mathrm{~mW} / \mathrm{cm}^{2}$. In step B (Figure 2B), the $1 \mathrm{~mm}$ thick OSTE+ middle-layer was photo-structured onto the bottom-layer by using a photomask and UV-light exposure for $250 \mathrm{~s}$ at $12 \mathrm{~mW} / \mathrm{cm}^{2}$. A paper printed in black was included under the OSTE+ bottom-layer to reduce reflections during photolithography. The resulting structures were developed by rinsing the layer in acetone, removing uncured monomers. In step $\mathrm{C}$ (Figure $2 \mathrm{C}$ ), the 1 $\mathrm{mm}$ thick OSTE+ top-layer was photo-structured by using a photomask and UV-light exposure for $200 \mathrm{~s}$ at 12 $\mathrm{mW} / \mathrm{cm}^{2}$. The resulting through-holes were developed by rinsing the layer in acetone. In step D (Figure 2D), the top-layer was aligned and clamped to the already combined bottom- and middle-layer. Bonding reactions were initiated via UV-light exposure for $500 \mathrm{~s}$ at 12 $\mathrm{mW} / \mathrm{cm}^{2}$. In addition, the bonding process was accelerated by placing the microdevice in the oven at 75 ${ }^{\circ} \mathrm{C}$ for $1 \mathrm{~h}$.

\section{EVALUATION}

During the fabrication process, each resulting layer was visually inspected after lithography using a lightmicroscope and the bonding of the completed microdevice was evaluated by filling it with dyed water using a syringe. In addition, the static contact angle for water on OSTE+ 1:1.4:0.4 was determined using the sessile drop method.

\section{RESULTS AND DISCUSSION}

The photolithography of OSTE+ on a silanized silicon substrate was tested by using a plastic photomask and by using a PDMS spacer to control the pillar height. Using OSTE+ 1:1.2:0.2, pillars with a height of $2 \mathrm{~mm}$, a diameter of $200 \mu \mathrm{m}$, and thus, an aspect ratio of 1:10 were manufactured (Figure 4). The minimum size feature that can be photo-structured and the maximum aspect-ratio that can be obtained using OSTE+ have yet to be determined. In addition, mechanisms and parameters for photolithography in OSTE+ need further investigation. For higher aspect-ratios than 1:10, the pillars featured cone shapes. This is believed to have been caused by the use of too thick polymer layers and/or too small photomask features. All pillars were sagging when the exposure time was $\sim 100 \mathrm{~s}$ shorter than $500 \mathrm{~s}$. This was likely caused by a too short exposure time leading to inferior mechanical properties of the polymer. Thus, it is important to optimize parameters affecting the lithography, such as photomask-to-polymer distance, layer thickness, exposure time, and polymer formulation, in order to find a suitable process window.

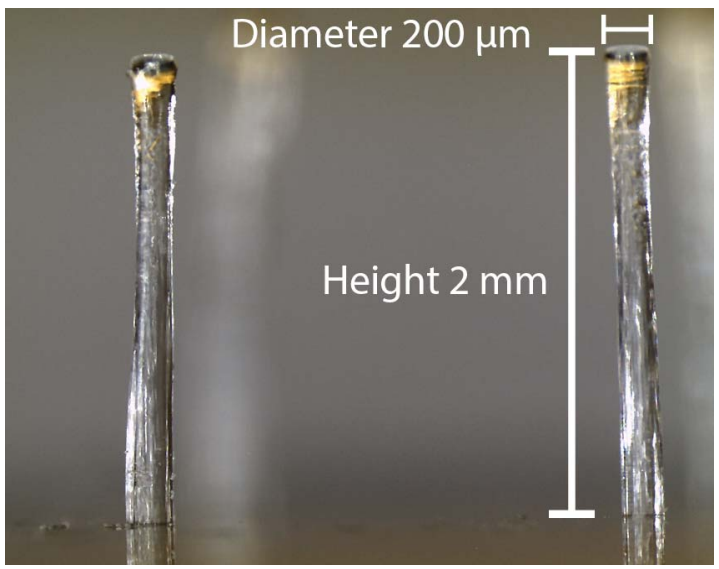

Figure 4: Micropillars of OSTE + with an aspect-ratio of 1:10 on silanized silicon.

To investigate whether direct lithography can be used to fabricate OSTE + microdevices, a three layer OSTE+ microdevice was fabricated (Figure 5). Each resulting layer had a thickness of $1 \mathrm{~mm}$, and the resulting microsized structures were all created by direct lithography. These structures consisted of: inlet holes $(1 \mathrm{~mm}$ in diameter), channels ( $250 \mu \mathrm{m}$ wide), and micropillars (height of $1 \mathrm{~mm}$ and diameter of $500 \mu \mathrm{m}$ ) (Figure 5C). The photo-structured top- and middle-layer was successfully bonded together using only $500 \mathrm{~s}$ of UV-light exposure and $1 \mathrm{~h}$ of $75{ }^{\circ} \mathrm{C}$ heat treatment. Due to the mechanical properties of this particular OSTE+ 1:1.4:0.4 formulation, the resulting microdevice was stiff and robust at room temperature. In addition, the microdevice was filled with dyed water using a syringe and was found to be leak-free under visual inspection. Furthermore, the contact angle of water on OSTE+ 1:1.4:0.4 was determined to be $67^{\circ}$ (material variation of $\pm 5^{\circ}, n=4$ ). Such device dimensions and surface properties demonstrated here cannot be readily obtained with OSTE, conventional PDMS or SU8 (Table 1).

Table 1: Comparison of polymers for fabrication of microfluidic devices

\begin{tabular}{|l|c|c|c|c|}
\hline Material: & PDMS & SU8 & OSTE & OSTE+ \\
\hline $\begin{array}{l}\text { High } \\
\text { aspect-ratio } \\
\text { lithography }\end{array}$ & - & $1: 18$ & $1: 8$ & $\begin{array}{c}1: 10 \\
{[\text { This }} \\
\text { study] }\end{array}$ \\
\hline $\begin{array}{l}\text { Max. layer } \\
\text { thickness } \\
\text { for photo- } \\
\text { lithography }\end{array}$ & - & $0.5 \mathrm{~mm}$ & $\begin{array}{c}>0.4 \\
\mathrm{~mm} \\
{[9]}\end{array}$ & $\begin{array}{c}2 \mathrm{~mm} \\
{[7 \mathrm{This}} \\
\text { study] }\end{array}$ \\
\hline $\begin{array}{l}\text { Original } \\
\text { surface } \\
\text { property }\end{array}$ & $\begin{array}{c}\text { Hydro- } \\
\text { phobic }\end{array}$ & $\begin{array}{c}\text { Hydro- } \\
\text { phobic } \\
{[10]}\end{array}$ & $\begin{array}{c}\text { Hydro- } \\
\text { philic } \\
{[6]}\end{array}$ & $\begin{array}{c}\text { Hydro- } \\
\text { philic }\end{array}$ \\
\hline $\begin{array}{l}\text { Dry } \\
\text { bonding }\end{array}$ & $\begin{array}{c}\text { Requires } \\
\text { plasma }\end{array}$ & Difficult & $\begin{array}{c}\text { Good } \\
{[6]}\end{array}$ & $\begin{array}{c}\text { Very } \\
\text { good } \\
{[8]}\end{array}$ \\
\hline
\end{tabular}




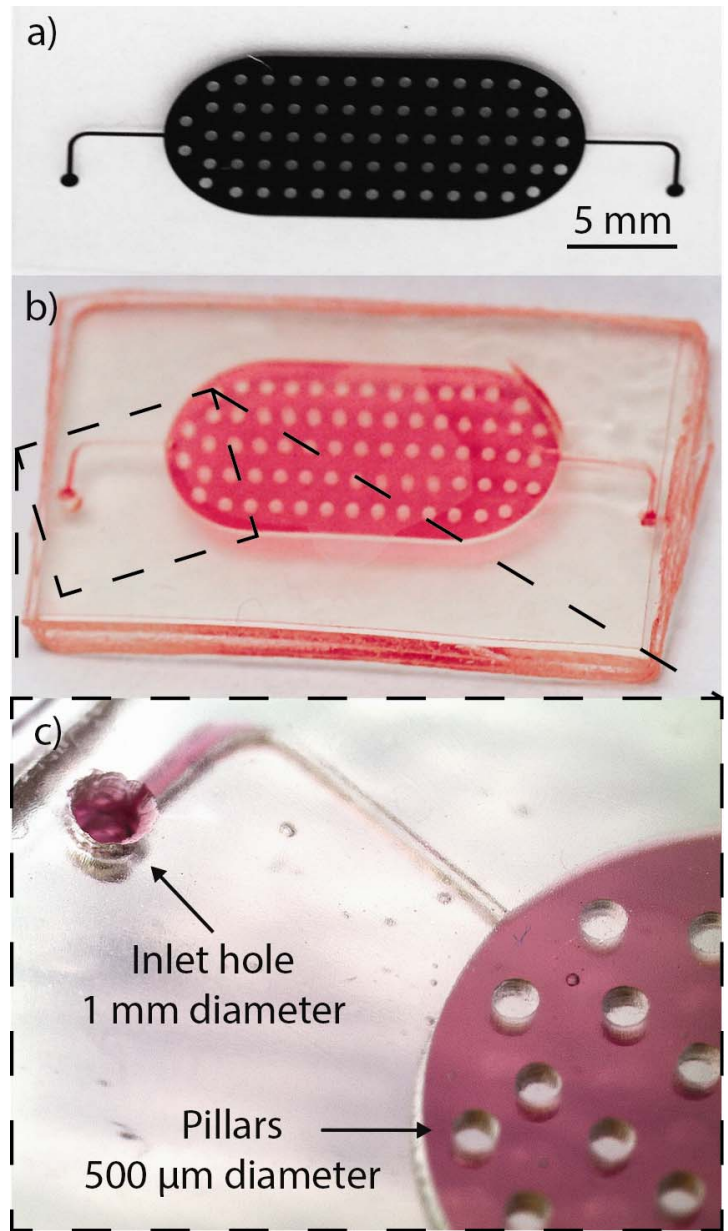

Figure 5: a) Plastic photomask used for direct lithography of the middle-layer. b) Photograph of the three-layer OSTE+ microdevice filled with dyed water. c) Close-up photograph of the microdevice

\section{CONCLUSION}

In this study, it was shown that OSTE+ microdevices can be fabricated by using the combination of direct lithography and direct adhesive-free bonding. In our experiments, we fabricated OSTE + micropillars with an aspect-ratio of 1:10, which highlights the photolithographic feature of OSTE+. We also showed that $1 \mathrm{~mm}$ thick OSTE+ layers can be photo-structured using direct lithography and can then directly be bonded to each other, without using adhesives or surface treatment.

In summary, microdevice fabrication using direct lithography in OSTE + provides a versatile alternative to soft lithography molding techniques and SU8-based photolithography. The resulting structures after lithography show the promising properties of OSTE+ polymers for microdevice manufacturing.

\section{ACKNOWLEDGEMENTS}

This work was financed in parts by the EU sponsored IMI project RAPP-ID, the EU sponsored FP7 project ROUTINE, and by the EU sponsored ERC-grant XMEMS. We also thank Mercene Labs AB for providing the OSTE+ monomers.

\section{REFERENCES}

[1] H. Becker and L. E. Locascio, "Polymer microfluidic devices," Talanta, vol. 56, no. 2, pp. 267-287, 2002.

[2] P. Abgrall and A.-M. Gué, "Lab-on-chip technologies: making a microfluidic network and coupling it into a complete microsystem - a review," Journal of Micromechanics and Microengineering, vol. 17, no. 5, pp. R15-R49, 2007.

[3] J. F. Ashley, N. B. Cramer, R. H. Davis, and C. N. Bowman, "Soft-lithography fabrication of microfluidic features using thiol-ene formulations," Lab on a Chip, vol. 11, no. 16, pp. 2772-2778, 2011.

[4] J. P. Lafleur, R. Kwapiszewski, T. G. Jensen, and J. P. Kutter, "Rapid photochemical surface patterning of proteins in thiol-ene based microfluidic devices," The Analyst, vol. 138, no. 3, pp. 845-849, 2013.

[5] T. M. Sikanen, J. P. Lafleur, M.-E. Moilanen, G. Zhuang, T. G. Jensen, and J. P. Kutter, "Fabrication and bonding of thiol-ene-based microfluidic devices," Journal of Micromechanics and Microengineering, vol. 23, no. 3, p. 037002, 2013.

[6] C. F. Carlborg, T. Haraldsson, K. Öberg, M. Malkoch, and W. van der Wijngaart, "Beyond PDMS: off-stoichiometry thiol-ene (OSTE) based soft lithography for rapid prototyping of microfluidic devices," Lab on a Chip, vol. 11, no. 18, pp. 31363147, 2011.

[7] J. M. Karlsson, F. Carlborg, F. Saharil, F. Forsberg, F. Niklaus, W. van der Wijngaart, and T. Haraldsson, "High-Resolution Micropatterning of OffStoichiometric Thiol-enes (OSTE) Via a Novel Lithography Mechanism," presented at the Proceedings Micro Total Analysis Systems (microTAS) 2012, pp. 225-227.

[8] F. Saharil, F. Forsberg, Y. Liu, P. Bettotti, N. Kumar, F. Niklaus, T. Haraldsson, W. van der Wijngaart, and K. B. Gylfason, "Dry adhesive bonding of nanoporous inorganic membranes to microfluidic devices using the OSTE $(+)$ dual-cure polymer," Journal of Micromechanics and Microengineering, vol. 23, no. 2, p. 025021, 2013.

[9] H. Lorenz, M. Despont, N. Fahrni, J. Brugger, P. Vettiger, and P. Renaud, "High-aspect-ratio, ultrathick, negative-tone near-UV photoresist and its applications for MEMS," Sensors and Actuators A: Physical, vol. 64, no. 1, pp. 33-39, 1998.

[10] M. Nordström, R. Marie, M. Calleja, and A. Boisen, "Rendering SU-8 hydrophilic to facilitate use in micro channel fabrication," Journal of Micromechanics and Microengineering, vol. 14, no. 12, pp. 1614-1617, 2004.

\section{CONTACT}

*A. Vastesson, tel: +46(0)703540845; vaste@kth.se 